\title{
Rahvameditsiini uurimisaine ja -meetodid
}

\author{
Carl-Herman Tillhagen
}

Sümpoosioni ${ }^{1}$ viimane istung oli tulemuste arutelu. J utuajamisel keskenduti uurimismaterjalidele ja -meetoditele. J ärgnev on diskussiooni lindistuse litereering. Vähemtähtsad osad ol en välja jätnud ja ülejäänus tegin ainult väheseid keel elisi parandusi. I stungit juhatas dr Odd N ordland, kes kutsus esimesena esinema professor Karl Robert Villehad (Ville) Wikmani.

Karl Robert Villehad Wikman: Sümpoosioni põhiteema on tohutult lai ja mitmetahuline. Me võime - nagu oleme siin ka teinud - vaadel da rahvameditsiini seoses meditsiiniajaloo, usundiloo, folkloori, meditsiini ja isegi veterinaariaga. Samas võime rakendada psühholoogilisi ja sotsioloogilisi põhimõtteid, uurida seda haridusajal oo vms kaudu. Rahvameditsiini uurimine nõuab seepärast koostööd sotsiaalantropol oogide, etnograafide, usundiloolaste, meditsiiniajaloolaste, psühholoogi dejt teadusharude esindajatega. Peame tegema koostööd, järgides sümpoosionil kuuldut. Kuniks teostamealusuuringuid, piisab meilevarasemast meditsi inilisest ja rahvameditsiinilisest kirjandusest - võime koostada antud ainesele sobivad bibliograafiad, uurida välja vallaarstide aruannetes, ämmaemandatekäsiraamatutes, arhiivimaterjalides jms sisalduva.

Albert Eskeröd: Esitan küsimuse, mida peaks küsima mitte ainult rahvameditsiini uurija, vaid ka iga teine rahvakultuuri uurija: millised on meie eesmärgid ja milliseid meetodeid peaksime kasutama nende saavutamiseks? Üleüldiselt on võimalik eristada kahte erinevat meetodit rahvakultuuri uurimisel: ühelt poolt on meil ol emas ajalooline ehk vertikaalne meetod, teisalt etnosotsioloogiline ehk horisontaalne meetod. Lääne materjali uurimisel peame alati arvestama ajal ool ist vaatenurka, kuid samal ajal ei saa me hakkama horisontaalse meetodi abita. Ärgem unustagem, et kõik materjalid ei sobigi ajalooliseks käsitluseks. Mõtlen siinkohal eriti algelist ainest, mida ei saa käsitleda formalistlikustki seisukohast, ajal oolisest rääkimata. Kui võtame näiteks "sidumise" ja kõhulahtisuse probleemid, siis nii palju kui mina asja näen, saame seda vaadel da ajal ool iselt. Ka tul esüütamist tuletaelaga või b vaadel da aja- 
looliselt. Uurides andmeid etnosotsioloogilisel meetodil, saamekasutada kogu materjali. Horisontaalkihi uurimise eesmärgiks on hankida teadmisi ravija ja haige läbisaamise, targa populaarsust määravate asjaol ude vms kaudu. E el nevat arvestades tahan öel da: peametöötama läbi nii palju ajalool ist materjali, kui saame, ja püüdma seada seda mingisse süsteemi. E daspidi peaksime pühkima tolmu ka hilisemalt materjalilt ja tegema selle võimaluste piires teadlastele kättesaadavaks. Kuid see on suur ettevõtmine. Carl-Herman Till hagen oma kartoteegiga Nordiska museetis on juba alustanud praeguseks ka osaliselt vilja kandnud tööd. Nii loome ülevaate meie kasutada ol evast materjalist - sellel võib olla tohutu väärtus tulevaste uuringute seisukohalt.

Lauri Honko: Kui rääkida Põhjamaid puudutavast materjalist, siis on meie teadlastel seda tõesti tohutult, kuid kahjuks jääb sellest väheseks. Ainuüksi Tillhageni kollektsioonis on üle 60000 teate ja meil Helsingis kaks korda rohkem. Oma Krankheitsprojektile kirjutamisel püüdsin saavutada detailsema ja konkreetsema pildi ühest kindlast maagilisest rituaalist, aga sattusin ikka raskustesse, vaatamata meel etule materjal ihulgale. Pilt oli liiga killustatud. Materjal sisaldas loitsu siit, loitsu sealt, kuid ei ol nud ühtegi seostatud detailset sel etust kõi kide üksikasjade või uuritavate rituaalide kohta tervikuna. Nii seisamegi jälle silmitsi lahendust nõudva tegeliku probleemiga: kuidas me nüüd, eelviimasel tunnil, hangime ammendava, teaduslikult arvestatava materjali?

Åke Hultkrantz: Sooviksin võtta Albert E skerödil sõnasabast kinni ja jätkata arutelu, mis puudutab erinevaid rahvakultuuri uurimismeetodeid. Sellel sümpoosionil on esindatud paljude erialadeteadlased, kes on erinevatel põhjustel huvitatud ühisest eesmärgist, mille keeruline ol emus nõuab otseseid ja laiaulatuslikke lahendusi. I gal teadusel on oma kindlad huviobjektid ja uuri mismeetodid. Neid oli huvitav siin tundma õppida. Sellel sümpoosionil liikusime mööda pealiini, mis aval dub Carl-Herman Tillhageni töös ja loengutes, andes ühisnimetaja kõikidele esilekerkinud probleemidele. Sellelt keskteelt hargneme erinevatesse suundadesse. Meie seas on neid, keda huvitavad ebausk ja üleloomulikkus, mina ise kuulun nende hulka, kes rõhutavad üleloomuliku tähtsust. Vastukaaluks on meil rahvameditsiini ratsionaalsest osast huvitatud arstiteadlasi. Sellepärast ei saagi mejõuda kokkuleppel e kindla uurimismeetodi suhtes, vaid peame materjalile lähenema erinevatest vaatenurkadest. Kindlasti mõjub see uurimisele ergutavalt. Min- 
nes tagasi materjali juurde - Lauri Honkorääkis selle piiratusest. Oleme siin tegel enud peamiselt Põhjamaade ja E uroopa materjal iga. Usun, et rahuldava ülevaate saamiseks Põhjamaade rahvameditsiini probleemidest peame abiks võtma ka üldised, etnograafilised materjalid. Uurin ise religiooni ajalugu ning huvitun pigem tüüpilisest ja erakordsest kui spetsiifiliselt ajal ool isest - see on tingitud olemuselt võrdleva uurimissuuna struktuurist, mida püüan järgida. Lõpetuseks: sümpoosion on parim võimalik viis teaduslikeks diskussioonideks. Oleks tore, kui sellised sümpoosionid oleksid tulevikukonverentside eeskujuks. Niisugustel kokkutulekutel, kus 18-20 teadlast erinevatelt al adelt süvenevad intensiivse tööperioodi jooksul ühte kindlasse valdkonda, saavutatakse omavahel isiklik kontakt, mis on väga edasiviiv. M eie sümpoosioni tulemused on suurtest kongressidest palju paremad, sest teadlastevaheline koostöö sujus isiklikumalt ja lähedasemalt.

Robin Fåhræus: Viidates jälle Lauri Honkole: kas pole tõsi, et mei euuritav materjal järk-järgult kahaneb, iga aastaga üha kiiremini? Nagu ol eks seda vähehaaval kustutatud...

Carl-Herman Tillhagen: Olen nõus sellega, mi da toonitas Lauri Honko ja millele professor Robin F åhræus just tähelepanu juhtis meil, rahvapärimuse uurijatel, on lahendada kiirel oomuline probleem. Traditsioonid on alati kadunud, kuid mitte kunagi nii kiiresti kui praegu. Seda ei saa salata. Varasematel aegadel elasid traditsioonid staatilisemat elu ja muutused olid nii aeglased, et neid oli raske ühe põlvkonna jooksul märgata. Kirjaoskus ja tänapäeval teadmisi levitav massimeedia, meel elahutustööstus, sotsiaal ne revolutsioon, kõrge elustandard, jõudsalt kasvav kommunikatsioonivahendite efektii vsus -kõik see on teinud meie [20. - toim] sajandist järskude muutuste ajastu, mil tavad ja kombed vahetuvad tuulekiirusel. Kõlabju uhkelt, kui ütlen, et mul on 60000 rahvameditsiinialast Rootsi kultuuripiirkonda puudutavat ülestähendust, kuid pärimuse uurijad teavad, kui vähe seda tegelikult on. Need teated peaksid peegel dama kümneid tuhandeid fakte. Sellepärast on meil parimal juhul kaks näidet iga nähtuse kohta. Sotsiaalantropol oogia uuringud ei saa erinevalt usundi loo uuringutest jääda rahule sellega, mis on tüüpiline. Peamejõudma detailideni ja meie uurimisobjekt - vana talupojakultuur tervikuna - on nii määratult suur, et vajame erinevate teadusharude abi kõigi probleemide lahendamiseks. Ainult siis, kui meil on astronoomilisel hulgal näitematerjale, saamekinnitust kõigile vajalikel efaktideleja oleme võimel ised 
analüüsima üht teisega võrrel des, et leida lahendust, nagu on öelnud Koguja (Vana Testament, Kg 7: 27).

Nagu prof Robin Fåhræus juba märkis, piirab meid jätkuvalt informatsiooni kustutav aeg, mis kohustab meid otsima uurimiseks vajalikke tõendeid enne, kui kogu materjal ära uhutakse. Tulevastel kultuuriteadlastel ei ole meie võimalusi rahvakultuurialase materjali hanki mi seks algal likast: meie praeguse lohakuse tagajärjel on nad sunnitud toetuma oma uuringutes puudulikuleja tihti äärmiselt lühiajaliseleja pinnapeal sel e tõendusmaterjalile, mida kogusid ettevalmistuseta üliõpilased või kohalikud korrespondendid, kel tavaliselt ei ole mingit ettekujutust teaduslikest meetoditest ja probleemi käsitlustest. Loomulikult ei korrasta need kogujad materjali hädavajaliku järjekindluse ja mõistmisest hingestatud teadusliku täpsusega. Sagedasti piirduvad nad kergelt kättesaadava pinnapealse ainese ja lisaks mõne kummalise tähelepanekuga. Kahjuks on õpetlased keel dunud mõistmast, et neil endil tuleb kogumises kanda olulist osa. Õpetlaste teoste ja eel nenud ajastu kirjaliku materjali uurimist on peetud välitöödest tähtsamaks ja teadusl ikumaks ning sel lepärast koguvad napimat koolitust saanud isikud seda materjali, mida kabinetiõpetlased toi metavad ning hool ikalt läbikaal utud teadusl ike uurimismeetoditega, suure vaeva, süvenemise ja tõsidusega analüüsivad. Olen alati arvanud, et selline töökorraldus on vale. Eriti kahetsusväärseks teeb selle asjaolu, et paljud keerul ised ja rasked probleemid tekivad välitööde ajal ja nendega tuleb tegelda kogumise käigus. Kogu meie intelligentsusest ei piisa nende probleemide lahendamiseks, nagu ei anna ka materjali puudulikkus meile vajalikke suundi. I segi siis, kui meil on ligi pääs heal e allikmaterjalile, nõuavad paljud rahvausundiga seotud probleemid - eriti rahvameditsiin - teatud liiki emotsionaalset intelligentsi, loomulähedust rahvaliku mõtteviisiga ning seda on kabinetiteadlasel raske saavutada. Oskus mõista intuitiivselt vana rahvausundit näib kaduvat sama kiirusega nagu taanduvad ja asenduvad vanaaegsed rahvakombed tänapäevaühiskonna standardiseeritud kooliharidusega.

Seega on tähtsaimaks ülesandeks koguda ja küllal daselt töödelda materjali, kuniks meil on selleks võimalusi. Lubagem endale kogumise naudingut.

Karl Robert Villehad Wikman: Adolf Bastian on öel nud: "Kogu etnograafiline maailm põleb. Kiirustage, kiirustage, kiirustage!" 
Materjali kogumine on kindlasti vajalik. Küsimustike ja kohalike korrespondentide abiga kogumine või b si iski osutuda pigem margikogumiseks, juhul kui me ei ole pidevalt teadlikud vajadusest arvestada materjali funktsiooniga. Kogenematul inimesel on seda kogumise ajal raske meeles pidada. Seepärast ei peaks õpetlane rahule jääma üksnes sellise materjaliga. Ta peab ise minema välitöödele, oma töömeetodi ja uudishimuga.

Eliel Lagercrantz: Oleme siin arutanud meetodeid ja materjale. Kui nüüd vaadel da rahvameditsiinialast ainest, siis etnograafilisest vaatenurgast on see liiga kasin. Pealegi on raske saada arvestatavat materjali. Suures osas puudub vajalik kirjandus mitteainult siin, Põhjamaades, vaid ka Euroopas tervikuna. Kui mõned aastad tagasi pidin süüvima ühte Lõuna-Ameerikat puudutavasse probleemi, suutsin Euroopast kokku laenutada ainult $20 \%$ vajalikust 400 teosest. Ülejäänu pi din Ameerikas mikrofilmi dele võtma. Niipalju kui asi puutub meetoditesse, siis ma ei nõustu sellega, mi da Albert E skeröd ütles näiteks "sidumise" kohta. Mis siis sellest, kui uurimustulemus on $95 \%$ osas negatiivne. Ülejäänud $5 \%$ võib näidata, et meetod eksisteeris hotentottide ja bušmanite juures, kuid mitte ainude seas. I segi sel line tulemus on edasiminek. Ka täielikult negatiivne tulemus või b olla meie jaoks positiivse tähendusega, sest nii võime antud teema uurimise tul evikus kõrvale jätta.

Odd Nordland: Rahvameditsiini puhul polekahtlust, et targad rakendasid kõrgelt arenenud sugestioonitehnikat. Kas võib oletada, et tänapäeva meditsiin saab seda kuidagi viisi rakendada? Tahaksin küsida professor Robin Fåhræusilt, kas meditsiinitudengid saavad sellealast koolitust.

Robin Fåhræus: Ma ei tea, kas nad praegu saavad sellist koolitust, kuid minu noorusajal küll mitte. Muidugi pidime me omandama meel diva "voodiäärel istumise" kombe, kuid meid ei õpetatud mingilgi määral kasutama sugestiooni.

Odd Norland: Tegelikult on see hämmastav, kui palju vanu uskumusi on jäänud nüüdisaegses rahvameditsiinis ellu. Mulleisiklikult on Norras korduvalt teatatud uskumustest, millega inimesed ikka veel arvestavad. J ärelikult peaks siiani olema võimalik koguda sellekohast materjali.

Robin Fåhræus: Ka oleks huvitav teada saada, kui kiiresti vanad rahvatarkused asendatakse. Kas ei oleks hea idee iga kümne aasta tagant teha pärimuse kadumisekiirust määravaid uuringuid? 
Odd Norland: Võib-olla, kuid meil puuduvad väljaõppinud inimesed, kes suudavad leida ja kättesaadavaks teha siiani säilinud pärimusmaterjali.

Åke Hultkrantz: Kogu eel nev kaeblemine materjali puudulikkuse üle paneb mind kurvastama. Oma uuringutes olen lähtunud eelkõige materjalist, mis tuli väljastpoolt Euroopat. Olen puudutatud, kui räägite 6000 või rohkemast teatest - mõnekogukonna puhul väljaspool Euroopat võib olla kõigest 10-15 teadet ja nii on paljude hõimude ja rahvaste puhul. Õigete järelduste tegemise teeb raskeks asjaolu, et maailmas on kogutud nii vähe rahvameditsiinialast materjali. Kuulates siinseid avaldusi, võin ainult õnnitleda Põhjamaade folkloriste, sest teil on kasutada nii tohutu materjalihulk. I metlen ja kadestan teid.

J ohn Granlund: Tahaksin ära märkida, kui oluline on sümpoosioni ettekanneteavaldamine ilma tavapärase, artiklit tundmatuseni muutva toimetamiseta.

Carl-Herman Tillhagen: Luban anda endast parima, et saavutada kaastööde trükkimineesitatud kujul. Palun esinejaid teha need mitte ainult lugemist väärivateks, vaid ka loetavateks. Selge ja konkreetne sisu selges ja veatus vormis peaks ol ema meie motoks.

Karl R obert Villehad Wikman: Meiesümpoosion hakkab lõppema. Tahan avaldada lootust, et selline õpetlaste suhtlemisviis jätkub ja muutub tavaks. Nagu varem juba öeldi, on sümpoosioni vorm väga väärtuslik ja innustav. Rahvameditsiin köi dab meid oma lugematute probleemidega, mis seostuvad paljude, mitteainult siin esindatud uurimisval dkondadega. Kui mainida ainult väheseid, on meil näiteks puudu teadlastest, kes esindaksid õppimisajalugu, psühhiaatriat ja psühhol oogiat. Loomulikult peaksimesellistel nõupidamistel kohtuma regulaarselt. Pakun välja, et võiksime meie edusammude juhendamiseks moodustada väikese, energilise, eelistatavalt Stockhol mis asuva komitee, mis valmistaks ette sümpoosione ja ol eks meid ühendavaks lüliks.

Odd Nordland: Selline ettepanek tundub suurepärane. Arvan, et küsimus laheneb kõige paremini, kui valime endi seast kindlad inimesed, kes võtavad endale vastutuse töötada selles komitees. Või on äkki teisi ettepanekuid? Tundub, et ei ole - jätkame selle küsimusega hiljem kirja teel. Kuna enam ei ole ka esinejaid, kuulutan arutelu lõppenuks ja pöördun dr Carl-Herman Tillhageni poole, et ta teeks saavutatust lühikese kokkuvõtte. 
Carl-Herman Tillhagen: Nende väheste päevade jooksul tabas mind mõistmine, kui erinevad me õpetlastena tegelikult oleme. Selle laua ümber pol e kahte sarnast teadlast. Nii et: Wieeiner ist, so ist sein Gott. / Darum ward Gott so oft zu Spott. ${ }^{2}$ Kui olla aus, siis võime ükskõik kui palju püüda olla objektiivsed, kuid inimestena näeme ühtesid asju selgelt, teisi aga ei märkagi.

Sellepärast on oluline kohtuda, nagu praegu. Ühinen Ville Wikmani ja ÅkeH ultkrantzi kiidulauluga sümpoosionile. Nagu vana rahvatarkus ütleb: mesilased eksivad ilma mesilasemata teelt. Sümpoosion peab saama meie mesilasemaks.

Oleme valinud raske ala. Rahvameditsiini maailmas on vanad kontseptsioonid segunenud uuemate uskumusel ementidega ja need põhimõtted on pai guti meie ratsionaalsele maailmale võõrad. Sellepärast on neid probleeme raske lahendada ja materjal on teksti tõl gitsemise tulemusel täis vigu ja väärtõl gendusi.

Me ei saa uurida rahvameditsiini kui iseseisvat nähtust. Me ei tohi kunagi unustada, et rahvameditsiin on meie vaimset rahvakultuuri määravate suurte kontseptsioonide ja kujutluste kompleksi koostisosa. Et uurida osa, peame tundma tervikut. Kui meil on N ordiska museetis 60000 rahvameditsi initeadet, peame arvestama ka 800000 teatega teiste vaimse rahvakultuuri osade kohta. Meil peab olema sellest materjalist vähemalt üldine ettekujutus, vastasel juhul muutuvad tekstid mõistetamatuteks ja me satume eksiteele.

Meie teemaks oli “Teaduslik ja pärimuslik traditsioon rahvameditsiinis". Nõupidamise ajal lähtusime selleteema erinevatest vaatenurkadest, kuid loomulikult jäi see ammendamatuks. Olimerohkem huvitatud pärimuslikust traditsioonist. Selle põhjenduseks on minu arvates asjaolu, et rahvalik osis moodustab val dava osa rahvameditsiinist. Kuid paljudes ettekannetes kuulsime, kuidas akadeemilinetraditsioon on imbunud rahva teadvusse ning mõjutanud mõtteid ja tegusid. Mulle tundub, et akadeemiline ja rahvapärane traditsioon on nagu kaks voolu, mis kulgevad paralleel selt. Rahvapärane traditsioon on nagu lai ja võimas jõgi, mis kulgeb läbi aja üsna sõltumatult oma ümbrusest, akadeemiline traditsioon on aga palju kitsam jõeke. Kuid neid kahtejõge ühendab palju erinevates kindlasti ajal ooliselt teineteist mõjutanud.

Ei tohi alahinnata ka sümpoosioni praktilist väärtust. Õppisime tundma üksteist ning üksteise meetodeid ja huve. Lõhkusime maha (kaitse)müüri, mis tavaliselt kasvab naabermaade vahel väga kõr- 
geks ja piilusime vastastikku üksteise töömaadele. I segi teadusmaailmas võib inimfaktor põhjustada probleeme. Kui on õpitud nägema asju teisteinimesteja teistealade teadlaste vaatenurgast, kahaneb risk olla liiga ühekülgne.

Kuulasimeerinevaid loenguid. J ohn Granlundi, Åke Hultkrantzi ja Lauri Honko puhtalt metodol oogilisi ettekandeid, mis olid heaks näiteks erinevatest rahvakultuuri uurimise meetoditest. Lily Weiser-Aalli, J ohn Granlundi ja Carl Christian Matthiesseni ettekanded esindavad ajal oolist ehk vertikaal set ning Åke Hultkrantzi, Lauri Honko ja Eliel Lagercrantzi omad etnosotsioloogilist ehk horisontaalset suunda. Mõlemad uurimissuunad on ol ulised ja tihti on vaja need kaks kokku viia. Kuulasime ka täi esti monograafilisi loenguid. Selle näiteks on dr Elisabet Dillneri inimlikkusest, mõistmisest ja praktilisest psühholoogiast juhinduv ettekanne. Peaksimegi rohkem selliseid ettekandeid kuulama, sest meie põhiline huviobjekt on Inimene kõigi tema irratsionaal sete probleemidega. Seejärel kuulasime Odd N ordlandi ja Kustaa Vilkuna ettekandeid, mis heitsid valgust rahvaravitsejate elule. Olav Bø ettekanne puudutas rahvameditsiini ratsionaalset poolt ja prof Robin Fåhræus andis mõningase meditsiinilis-ajal ool ise ül evaate rahvameditsiini ainesest. Kõik need esinemised, nagu ka ettekannetele järgnenud arutelud, val gustasid meie uurimi sval dkonda erinevatest vaatenurkadest ja lei dsime mitte ainult vastuseid, vaid kerkisid ka uued küsimused.

Mis on meie tulevikuülesanded? Üleloomulik rahvameditsiin püstitab palju probleeme, paljusid ravimisviise peaks uurima eraldi, ravivahendid peaksid olema läbiuuritud ja ravimeetodid erinevate haiguste korral lähemalt vaadeldud. Oluliseks tööpõlluks nimetan rahvameditsiini "juhuseid" kus, millal ja kuidas. Praktiline meditsiin annab meile samapalju tööd. Rootsis valmistame ette uurimust praktiliste abivahendite ja ratsionaal sete ravi meetodite kohta tal upoegade seas. Nagu rääkis meile dr Olav Bø, töötatakse ka N orras samade probleemi de kallal. U urima peaks ka veterinaariat. Nordiska museetis valmistumegi detailseteks veterinaariauuringuteks, mis kulgevad paralleel selt inimeseuuringutega. Oleks huvitav teada, kuidas ülel oomulikud ravimeetodid on rakendatavad loomade juures, kes õigupool est ei tohiks sugestioonile alluda. Kas siin võib ol etada suurema hulga ratsionaal sete ravivahendite ja abi kasutamist võrreldes rahvameditsiiniga, mis puudutab inimesi? 
Meditsiinikirjandus on samuti tähtis ala. Püüdsin kogu hingest innustada mõningaid teadlasi koostama selle sümpoosioni tarvis bi bliograafiat kõi gist sellistest väljaannetest alates keskajast, märkustega publitseerimise arvu, leviku jnekohta. See mul kahjuks ei õnnestunud. Kindlasti peaks bibliograafia koostama, kuna see annab meile kahtlematult väärtuslikku teavet akadeemiliseja traditsioonilise rahvameditsiini vahendajatest.

Ka meditsiiniajal oo uuringutel on suur väärtus. Selle tulemused on hädavajalikud nii folk kloristidel e kui ka usundi lool astele, sest need annavad kindla al use hindamaks pärimusliku meditsiini kontseptsioone.

Suurima tähtsusega on primitiivsete rahvaste meditsiini uurimine. Åke Hultkrantz ja Eliel Lagercrantz mõlemad rõhutasid sellega seotud materjali puudulikkust. Kas võime jääda lootma UNESCO huvile selle ala vastu? Arengumaade rahvaste kommete ja tavade säilitamine ja kogumine peaks olema kõige tähtsam töö. See kehtib suurel määral ka rahvameditsiini kohta, mis siiamaani moodustab nende elu koostisosa. Kas pol eks vaeva väärt teha kindlaks nende inimeste rahvameditsiini taust, aitamaks parandada nende hirmuäratavalt nigelaid tervishoiutingimusi? Primitiivrahvaste seas levinud, akadeemilisest traditsioonist mõjutamata kontseptsiooni de sel gitami ne peaks aitama mõi sta meie oma rahvameditsiini ja valgustama rahvapärase mõtlemisviisi integreerumise küsimust.

Kõik need probleemid vaevavad meid pikka aega. Kurvaks teeb asjaolu, et on liiga vähe teadlasi, kes tegelevad kesksete aladega meie rahvausundis. Peaksime ol ema õnnelikud, kui sellel sümpoosionil õnnestus suurendada huvi rahvameditsiini vastu. Vaevalt leidub kogu kultuuriuuringus teist sellist ala, mis sisaldab nii palju huvitavaid probleeme nagu rahvameditsiin. Psühholoogilise seostatuse vastu huvi tundvad teadlased leiaksid, et rahvameditsiin rahuldab nende isu tähtsate ja märkimisväärsete probleemidejärele.

Lõpuks tahaksin Nordiska museeti ja iseenda nimel tänada teid kõi ki vastamast kutsele tulla sümpoosionile. Tegelikult ol eme väga meelitatud, nähes siin ametliku meditsiini esindajaid: professorid Martin Bergstrand ja Robin F åhræus, dr Kock ja dr Holmgren. Eriti tahaksin tänada professor Robin Fåhræusi. Nautisimeteiejagatud suurepäraseid teadmisi nõupidamise ajal ning vai msusest hingestatud loenguid ja diskussioone. Kui meie, folkloristid, oleksime oma kokkutulekutel sama teravmeel neja võl uv sel tskond nagu teie, 
siis võiks meie uurimisharu isel oomustada la gaya scienza ${ }^{3}$ ja ol eksime saanud sell ele veel ühe austamist vääriva omaduse.

Tänan ka kõiki teisi. Nii eraisiku kui ka teadlasena rõõmustasid mind siia tulnud hallipäised mõttetargad, kes vaevalt lubasid endale aega söömiseks, kiirustades kohtumistele, aitamaks meid probleemide lahendamisel, hoolimata asjaol ust, et pingeline töö on kestnud kaks päeva järjest keskööni välja.

Lõpuks tahaksin tänada meie nestorit, professor Karl Robert Villehad Wikmanit. See õpetlane on enam kui keegi teine innustanud selle sümpoosioni toimumist. Ma ei tea, kui mitu kirja me vahetasime, ei tea, kui tihti oleme arutlenud akadeemilise ja rahvapärase teemadel minu kabinetis, kodus või mõnes restoranis. Kui siin meie seas on keegi, kes (kui kasutada Ville Wikmani enda vaimukat väljendit) on "sümpoosioni pea", siis on see kindlasti Ville Wikman. Ta on sümpoosioni ülempea! Meielugupidamiseja austuse märgiks on see plaat, mille ornamendis on muuseas purpurne merekarp ja see on mi dagi väga sümboolset. Kui hoida merekarpi kõrva kohal, siis kuuleme nagu merekohinat. J a kui me kuulame oma sõpra Ville Wikmanit, kuuleme samuti justkui meloodiat teadmiste mel oodiat, mille vaiel damatult kaunis koor koosneb paljudest paladest, mis kõlavad läbi aegade, alustades Platoni kojast kuni tänase sümpoosionini. Sooviksin sümpoosioni nimel esitada sel leK reeka tarkust ja sümboolikat täis mäl estuseseme meie sümpoosioni ülempeale!

Karl Robert Villehad Wi kman: Tänan teid! Tahan väljendada oma tänu sooviga, et sümpoosioni idee õnnestuks. Tere tulemast Turusse järgmisel aastal, kui kavas on šamanism.

Olav Bø: Tahan öelda kõigi siinolijate nimel tänusõnad meie võõrustajale, Nordiska musetile. Nautisime siinviibimist, meid innustati ja inspireeriti tööd jätkama. Suur tänu!

Odd Nordland: Nüüd si is, mu daamid ja härrad, on meie sümpoosion osa purpurse rannakarbi kohinast.

Tõlkinud Renata Sõukand

Originaal: Carl-Herman Tillhagen 1962-1963. Material and Research Methods within Folk-medicine. ARV: N ordic Yearbook of Folklore18/19, Ik 352-362). 


\section{Kommentaarid}

1 J utt on 1961. aastal Stockholmis N ordiska museeti eestvõttel korraldatud I Põhjamaade rahvameditsiinisümpoosionist (toim).

${ }^{2}$ Milline inimene ise, selline on ka tema jumal. / Seepärast pilgataksegi jumalt nii sageli (J ohann Wolfgang von Goethe, Zahme Xenien (Leebed kseeniad)).

${ }^{3}$ Lõbus teadus (itaalia k), sellist paralleel pealkirja kannab näiteks F riedrich N ietzscheluuletuskogu saksakeel setiitliga DiefröhlicheWissenschaft (toim). 